\title{
Numerical modeling of a seafloor hydrothermal system during incipient serpentinization
}

\author{
P. GOUZE, G. LODS, M. GODARD ${ }^{1}$
}

${ }^{1}$ Géosciences Montpellier, CNRS, Univ. Montpellier, France. Philippe.Gouze@umontpellier.fr

Serpentinization is ubiquitous in exhumed mantle peridotites along oceanic spreading center. It consists in the hydration of high density mantle minerals to produce lower density hydrated serpentine. It can generate up to $90 \%$ of serpentine over depths of $>7 \mathrm{~km}$ in less than few tens My, thus indicating that the permeability of the mantle basement is maintained while accommodating for the excess of solid volume produced by serpentinization over its duration. We built a numerical model to investigate the coupled hydrodynamical and chemical parameters controlling the serpentinization of mantle peridotites in these oceanic hydrothermal systems.

Serpentinization is exovolumic and exothermic, it consumes water and is controlled by temperature dependent kinetics. Accordingly, the model takes into account the cooling of the system, the occurrence of regional expansion due to the exhumation of peridotites and minimal porosity resulting from microscale local mechanical processes such as crystallization forces. The properties (e.g. viscosity and density) of the fluid and the solid species are temperature/pressure dependent and the reactive surface area and permeability are porosity dependent and modelled by parametrized power laws.

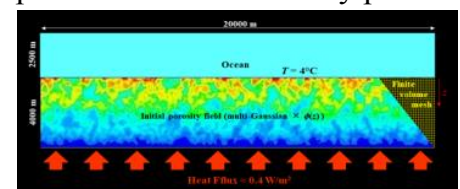

The model allows performing a relevant analysis of the parameters that control (i) the effective serpentinization rate and its spatial distribution, (ii) the time-space occurrence of the outlet zones at the ocean floor (figure below), and (iii) the flux and composition of the water of the hydrothermal vents, as well as the heat exchanges and $\mathrm{H}_{2}$ production at the ocean floor.

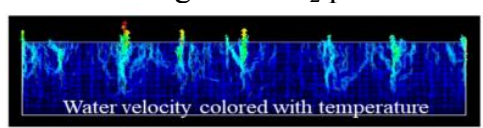

The results emphasize the critical control of the initial porosity heterogeneity, the cooling of the massif, the regional expansion and the effective reaction rate (i.e. the reaction kinetic and the reactive surface area changes). Heat flux is mainly controlling the serpentinization duration. 